City University of New York (CUNY)

CUNY Academic Works

\title{
The Impact of Receiver Aperture Design and Telescope Properties on LIDAR Signal-to-Noise Ratio Improvements
}

Yasser Hassebo

CUNY La Guardia Community College

Khaled El Sayed

Cairo University

\section{How does access to this work benefit you? Let us know!}

More information about this work at: https://academicworks.cuny.edu/lg_pubs/60

Discover additional works at: https://academicworks.cuny.edu

This work is made publicly available by the City University of New York (CUNY).

Contact: AcademicWorks@cuny.edu 


\title{
The Impact of Receiver Aperture Design and Telescope Properties on LIDAR Signal-to-Noise Ratio Improvements
}

\author{
Yasser Hassebo ${ }^{1}$, Khaled El Sayed ${ }^{2}$ \\ ${ }^{I}$ LaGuardia Community College of the City University of New York, Math/Engineering Department, USA \\ ${ }^{2}$ Department of Physics, Faculty of Science, Cairo University, Egypt
}

\begin{abstract}
Range and sensitivities of lidar measurements in daylight are limited by sky background noise power (BGP). This is particularly important for Raman lidar techniques where the Raman backscattered signal is relatively weak. This often restricts Raman lidar measurements to nighttime where BGP is absent. The background noise elimination is particularly important in daytime measurements in case where full overlap between laser beam and receiver telescope field-of-view (FOV) is necessary. Results of numerical simulations for a vertically pointing Lidar show that significant improvements in Lidar signal to noise ratio (SNR) can be obtained, by minimizing the detected sky BGP. This can be, optimally achieved if the receiver telescope aperture is properly designed to track lidar target images, which are range dependant. In this context, the connection between receiver telescope field of view and optimum aperture size are examined. The SNR improvements, which can be obtained in this manner, translate to corresponding improvements in Lidar range for backscatter schemes including Raman and DIAL.
\end{abstract}

\section{INTRODUCTION}

Light Detection and Ranging (lidar) is an active remote sensing instrument that transmits laser and measure the backscatter radiation after interacting with various components of the atmosphere. The impacts of aerosol in the human health with diseases such as lung cancer, bronchitis, and asthma have been essential motivations to record aerosol properties and transportation. Lidars have been applied to study stratospheric aerosols [1], tropospheric aerosols [2] and climate gases such as stratospheric ozone [3] as well as for analyzing the clouds properties [4]. In this work we examine the potential of improving SNR for monostatic lidar systems by analyzing and optimizing detector aperture (field stop) geometry. Monostatic lidar systems can be subdivided into two categories, coaxial and biaxial lidar systems. The main disadvantages in the coaxial lidar systems, where the transmitted laser beam is coaxially with the receiver's FOV, are the detector saturation problem that is occur once the lidar laser beam is shot, the unwanted signal that is detected from reflection of the transmitted light at the transmitter optics, in the top of the receiver telescope, and the part of images, for shorter range, that is blocked by the secondary mirror. Biaxial lidar, where the transmitter and receiver are located adjacent to each other, system is a practical solution to overcome these coaxial lidar systems problems. But, on other hand, the recorded data from the biaxial lidar is negatively affected by the geometrical factor (GF) at shorter range. To realize the effect of GF ' $\xi(R)$ ' in the return lidar signal, the lidar Equation can be written as [5]:

$$
P\left(\lambda_{L}, R\right)=P_{L} \frac{A_{o}}{R^{2}} \xi\left(\lambda_{L}\right) \beta\left(\lambda_{L}, R\right) \xi(R) \frac{c \tau_{L}}{2} \exp \left(-2 \int_{0}^{R} k\left(\lambda_{L}, R\right) d R\right)
$$

Where, $P\left(\lambda_{L}, R\right)$ is the total scatter laser power received from a distance $R, P_{L}$ represents the average power in the laser pulse, $A_{o} / R^{2}$ describes the solid angle of the receiver optics ( $A_{o}$ is the area of the telescope primary mirror), $\xi\left(\lambda_{L}\right)$ denotes the receiver's spectral transmitter factor, $\beta\left(\lambda_{L}, R\right)$ is the volume backscatter coefficient, $c \tau_{L}$ represents laser pulse length ( $c$ is speed of light, $\tau_{L}$ is Laser pulse rectangular duration), $k\left(\lambda_{L}, R\right)$ : Atmospheric extinction coefficient. The smaller the value of $\xi(R)$ is the smaller the return signal and the smaller SNR particularly for short distances. GF can be defined as the ratio of the energy transferred to the photodetector to the energy reaching the telescope primary mirror, $E_{\mathrm{det}} / E_{\mathrm{scat}}[6]$.This reduction in the detector response to the return

CP888, Modern Trends in Physics Research,

Second International Conference on Modern Trends in Physics Research-MTPR-06, edited by L. El Nadi

(C) 2007 American Institute of Physics 978-0-7354-0354-9/07/\$23.00 
signal is caused by a lack of perfect overlap between the receiver telescope's FOV and the transmitter laser beam. In Section 2, we discuss the overlap effect of the GF including the receiver field stop position and size, and their effect in lidar SNR improvement. Lidar simulation results are introduced in section 3. Also, the telescope best selection to reduce BGP is introduced in Section 4. Conclusions and future works are presented in Section 5.

\section{PROBLEM DESCRIPTION AND ANALYSIS}

The standard configuration for most lidars is to place a round aperture in the focal point of the receiver telescope. It is also commonly assumed that once the lidar receiver FOV and transmitted beam are completely overlapping, the efficiency of collection is unity ${ }^{5}$. However, this analysis does not properly take into account the shifted position of the collected backscattering signals on the image plane from the telescope focal point at the receiver. These shifting distance from the telescope focal point and the atmosphere sounding (image) size variation are according to the distance ' $b_{0}$ ' between the laser and telescope optical axis. This image displacement is range dependant as shown in Fig. 1. In fig 1. the telescope is presented by a lens with diameter of $t_{o}$ and $f$ focal length. The farther the lidar object $\left(Z=R_{\max }\right)$ the smaller the sounding image $\left(\operatorname{Im}_{1}\right)$, on the other hand the closer the lidar object $\left(Z=R_{\min }\right)$ the larger the sounding image $\left(\mathrm{Im}_{2}\right)$. Numerous papers implemented a wedge like shape aperture design to over come this shifted problems $[7,8]$. In this paper we study the effect of changing a round aperture, the realistic shape, size and place in the lidar SNR.

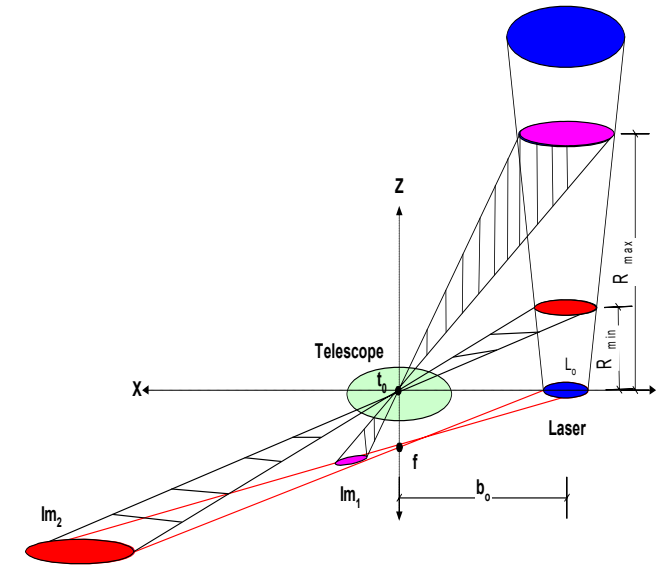

FIGURE 1. Biaxial Lidar, schematic diagram shows transmitter and receiver subsystems, and sounding trace images for lidar objects at heights of $\mathrm{R}_{\min }$, and $\mathrm{R}_{\max }$

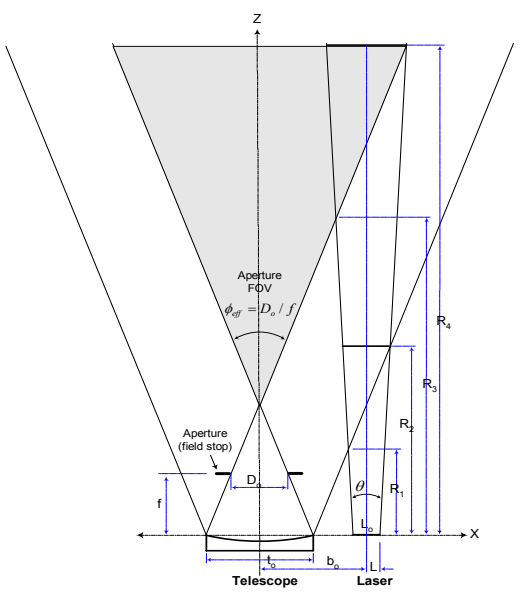

FIGURE 2. Biaxial Lidar: overlapping between effective FOV of receiver telescope (diameter of $t_{o}$ ) and laser beam (initial diameter $\mathrm{L}_{0}$ ) and aperture diameter $\mathrm{D}_{\mathrm{o}}$

As shown in Fig. 2, we assume the optical vertical axis $z$. the ground level (x-axis), where the location of the telescope primary mirror and the transmitted laser beam, is at $\mathrm{z}=0$. The range ' $R$ ' increases, there will be a point ' $R_{l}$ ' where the first intersection between the left boundary of the laser beam and the right boundary of the telescope FOV. Then at $\left(z=R_{2}\right)$ the complete overlap is formed with the telescope FOV. But this is not the effective overlap function. The effective FOV is based on, $D_{o}$, the field stop diameter and $f$ the telescope focal length $\left(\phi_{e f f}=D_{o} / f\right.$

the shaded area in this case) [9]. The actual overlap started at $\left(z=R_{3}\right)$ and finally the effective overlap is completed at $\left(z=R_{4}\right)$. At short distances $\left(z<R_{3}\right)$ the ratio of the overlapping area $\left(O L_{\text {area }}\right)$ to the image area $\left(\operatorname{Im}_{\text {area }}\right)$ that formed near to $(f)$ is

$$
\xi(R)=\frac{O L_{\text {area }}}{\operatorname{Im}_{\text {area }}}=0
$$

where $O L_{\text {area }}=0$. This is making near field observations impossible (effective telescope area: $\left.A_{\text {eff }}(R)=A_{o} \xi(R)=0\right)$. In the case of a small round aperture $\left(\mathrm{D}_{\mathrm{o}}=2 \mathrm{~mm}\right.$ diameter) is placed at the telescope focal pint $f_{o}$, the overlap function $\xi(R)$ is very small for any object in ranges of $\left(R_{3}<z<R_{5}\right)$, where at $R_{5}$ there is an arbitrary object which has 
a large sounding image that is formed very far from $f$ in the imaging plan (see Fig. 1). Design of a unique aperture to cover certain desired ranges becomes feasible.

\section{RESULTS}

In this paper we propose a feasible design of a round aperture to house certain desired ranges and minimizing the detected BGP. That can be achieved by moving the commonplace aperture $\left(D_{o}\right)$ center from the origin $\left(f_{o}\right)$ some distance to the left (depend on the object height) and reduces the aperture size from $D_{o}$ to smaller diameter $D_{s}$ (i.e., reducing the effective FOV from $\phi_{\text {eff }}=D_{o} / f_{o}$ to $\left.\phi_{\text {eff }}=D_{s} / f_{s}\right)$ where $f_{s}$ is a smaller telescope focal length. Lidar simulation results for biaxial system are shown in Fig. 3. This simulation is for the following parameters: The distance between the beam and the telescope axis is $b_{0}=200 \mathrm{~mm}$, laser initial beam diameter $\mathrm{L}_{o}=5 \mathrm{~mm}$, beam divergence $\theta=0.5 \mathrm{mrad}$, telescope primary mirror diameter of $\mathrm{t}_{\mathrm{o}}=178 \mathrm{~mm}$, and two different telescope focal lengths of $f_{s}=1.7 \mathrm{~m}, f_{L}=4 \mathrm{~m}$. We always are taking into account that $\theta$ is smaller than the effective telescope's FOV ( $\phi_{\text {eff }}=D / f$ ), both $D$ and $\mathrm{f}$ (the field stop diameter and the telescope focal length, respectively) have three different values. These values are: (1) $D=D_{o}=2 \mathrm{~mm}$, for commonplace aperture (placed at the telescope focal length $f=f_{o}$ ). (2) $D=D_{s}$ for small telescope focal length $\left(f=f_{s}=1.7 \mathrm{~m}\right)$. (3) $D=D_{L}$ for telescope with bigger focal length $\left(f=f_{L}=4 \mathrm{~m}\right)$. Obviously, the new aperture position and size reduction are range dependent. For shorter ranges $(0.5-5 \mathrm{~km})$ the aperture diameter became smaller (i.e., $D_{s}=1.8 \mathrm{~mm}$ for $f_{s}=1.7 \mathrm{~m}$ ) and the center is shifted by $\sim 0.45 \mathrm{~mm}$, on the other hand, if we use a bigger telescope, a field stop diameter of $D_{L}=4.7 \mathrm{~mm}\left(\right.$ for $\left.f_{L}=m\right)$ must be used. This bigger aperture (i.e., bigger BGP) center must be shifted by $\sim 2.4 \mathrm{~mm}$ that to housing the entire images. However, for higher lidar range $(5-25 \mathrm{~km})$ the field stop size gets much smaller $\left(D_{s}=1.4 \mathrm{~mm}\right.$ for $\left.f_{s}=1.7 \mathrm{~m}\right)$ that centered approximately at the origin $(0,0)$, but $D_{L}=3 \mathrm{~mm}$ center shifted by $\sim 0.5 \mathrm{~mm}$. We noted that the field stop shifted positions and sizes changing are more significant for the shorter ranges particularly for bigger telescope focal length.

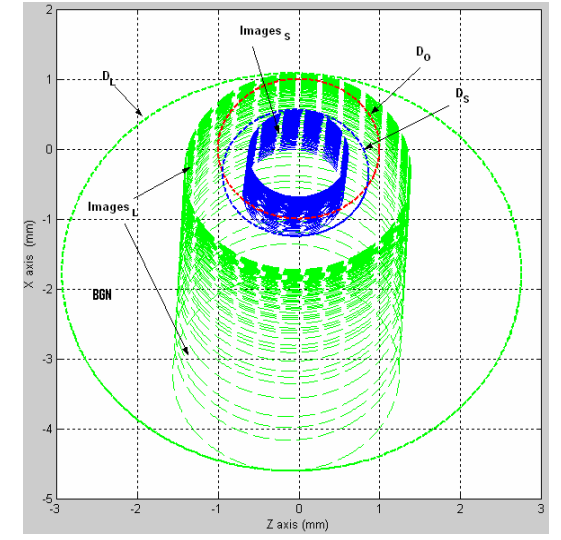

(a)

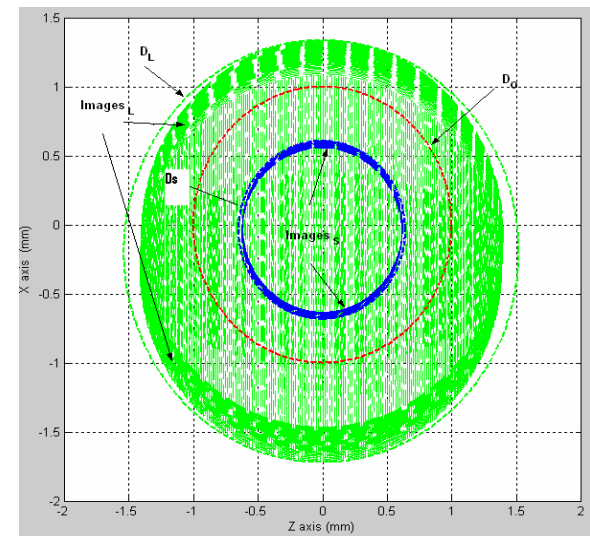

(b)

FIGURE 3. Lidar images (a) For range $500 \mathrm{~m}-5 \mathrm{~km}$. (b) For range $5 \mathrm{~km}-25 \mathrm{~km}$. The green images (images ${ }_{\mathrm{L}}$ ) for $4 \mathrm{~m}$ telescope focal length and the blue images (images s) for telescope with $1.7 \mathrm{~m}$ focal length. The commonplace aperture $\left(D_{0}=2 \mathrm{~mm}\right)$ placed at the telescope focal point, $\mathrm{D}_{\mathrm{L}}$ is a round aperture to accommodate (images $\left.{ }_{L}\right)$ and $\mathrm{D}_{\mathrm{S}}$ is a round aperture to accommodate (images $\mathrm{s}$ ).

\section{TELESCOPE SELECTION}

Typically in lidar measurements a larger $\mathrm{VOF}_{\text {eff }}$ is desired to decrease the height where the laser beam meets the effective telescope FOV for the first time $\left(z=R_{3}\right)$. The $\mathrm{VOF}_{\text {eff }}\left(\phi_{\text {eff }}=D / f\right)$ enlargement is required increasing the field stop size $(D)$ for the same telescope focal length $(f)$. Yet, the larger the $\operatorname{VOF}_{\text {eff }}\left(\phi_{\text {eff }}\right)$ is the bigger the BGP that reaching the PMT, beside the larger the multiple scattering effect $[9,10,11]$. This trade off can be optimized 
using two techniques. (1) If the laser beam is tilted toward the telescope by inclination angel $\Theta$ to increase the effective lidar range [12]. (2) Reducing $\mathrm{VOF}_{\text {eff }}$ by decreasing both field stop diameter $(D)$ and telescope focal length $(f)$, that the BGP increment can be avoided. Where, BGP is proportional to $\mathrm{VOF}_{\text {eff }}$ in the shot noise regime [13, 14]. As shown in our simulation results (Figs. $3 \mathrm{a}$ and $3 \mathrm{~b}$ ), the larger the telescope focal length $\left(f=f_{L}\right)$, is the larger the image size $\left(\operatorname{Images}_{\mathrm{L}}\right)$, and the larger the sky BGP mainly in shorter distance. Where $\left(\operatorname{Images}_{\mathrm{L}}\right)$ is the lidar sounding images collected through $\left(f_{L}=4 \mathrm{~m}\right)$ telescope focal length, and (Images $)_{S}$ represents the lidar sounding images collected through telescope with focal length of $\left(f_{S}=1.7 \mathrm{~m}\right)$ both from objects at ranges of $500 \mathrm{~m}-5 \mathrm{~km}$, and $5 \mathrm{~km}-$ $25 \mathrm{~km}$ as illustrated in Figs $3 \mathrm{a}$ and $3 \mathrm{~b}$, respectively. $\mathrm{D}_{\mathrm{s}}$, blue circle, and $\mathrm{D}_{\mathrm{L}}$, green circle, represent the round shape apertures that housing the entire lidar return signal using a $1.7 \mathrm{~m}$, and $4 \mathrm{~m}$ telescopes respectively. As cab be seen in table 1 , numerical results show that as much as a factor of $(17.8 \%)$ improvement in lidar signal-to-noise ratio if we used even smaller telescope $\left(f_{S}=1 \mathrm{~m}\right)$ over conventional large telescope $\left(f_{L}=4 \mathrm{~m}\right)$. That can be obtained if we assume that the mean value of the photomultiplier tube (PMT) output power $\left(P_{d}\right)$ is proportional to BGP (i.e., $\left.\left\langle p_{d}\right\rangle \alpha B G P \quad\right)$. Meaning the detector operates in the shot noise limit. A system under the shot noise limit if the detected noise amplitude (standard deviation) is proportional to the square root of the mean detected signal at the fare range (i.e. $\Delta P_{d}=\sqrt{\left\langle p_{d}\right\rangle}$. The potential of this work becomes visible if we compare the detected SNR with small and bigger telescope focal lengths. In the shot noise regime, the SNR improvement factor ( $\mathrm{SNR}_{\mathrm{imp}}$ ) can be expressed in terms of BGP corresponding to large and small telescope focal length ( $B G P^{L}, B G P^{S}$, where in this case $\left.B G P^{L}>B G P^{S}\right)[14]$ :

$$
S N R_{i m p}=\frac{S N R_{S}}{S N R_{L}}=\sqrt{\frac{P_{s i g} / B G P^{S}}{P_{s i g} / B G P^{L}}}=\sqrt{\frac{B G P^{L}}{B G P^{S}}}
$$

This formula shows that decreasing the sky background noise from $B G P^{L}$ to $B G P^{S}$ using smaller telescope focal length will improve the SNR. This SNR improvement can be translated into improvement in the attainable lidar range.

TABLE 1. Image's size versus telescope focal length for different lidar ranges. Effective FOV ( $\left.\phi_{\text {eff }}\right)$ is shown no big different in the higher range for a variety of $f$. Normalized $\phi_{\text {eff }}$ with respect to $\phi_{\text {eff }}$ of $(f=4 m)$ is also shown.

\begin{tabular}{|c|c|c|c|c|c|c|}
\hline \multirow{2}{*}{$\begin{array}{c}\text { Telescope } \\
\text { F }\end{array}$} & \multicolumn{2}{|c|}{ Lidar range ' $R$ ' } & \multirow{2}{*}{$\begin{array}{l}\begin{array}{c}\text { Aperture } \\
\text { diameter }\end{array} \\
\mathrm{D}_{\mathrm{L}}(\mathrm{mm})\end{array}$} & \multirow{2}{*}{$\begin{array}{c}\phi_{\text {eff }}=D_{L} / F \\
(m r a d)\end{array}$} & \multirow{2}{*}{$\begin{array}{c}\begin{array}{c}\phi_{\text {eff }} \\
\text { (Norm) }\end{array} \\
\% \\
\%\end{array}$} & \multirow{2}{*}{$\begin{array}{c}\mathrm{SNR}_{\text {Imp }} \\
\\
\% \\
\end{array}$} \\
\hline & From (km) & To (km) & & & & \\
\hline \multirow[t]{2}{*}{$4 \mathrm{~m}$} & 0.5 & 5 & 4.7 & 1.175 & 100 & 0 \\
\hline & 5 & 25 & 3 & 0.75 & 100 & 0 \\
\hline \multirow[t]{2}{*}{$3 \mathrm{~m}$} & 0.5 & 5 & 3.4 & 1.13 & 96 & 2 \\
\hline & 5 & 25 & 2.1 & 0.7 & 93 & 3.6 \\
\hline \multirow[t]{2}{*}{$1.7 \mathrm{~m}$} & 0.5 & 5 & 1.8 & 1.058 & 90 & 5.4 \\
\hline & 5 & 25 & 1.4 & 0.7 & 93 & 3.6 \\
\hline \multirow[t]{2}{*}{$1 \mathrm{~m}$} & 0.5 & 5 & 0.85 & 0.85 & 72 & 17.8 \\
\hline & 5 & 25 & 0.6 & 0.6 & 80 & 11.8 \\
\hline
\end{tabular}

By comparing the results in table 1 , give evident that a lidar system with small focal length $(f=1 m)$ is much better in reducing BGP than is any other system with big $(f=4 m)$ focal length telescope particularly for short distances. this deduction of the BGP can be translated to improvement in lidar SNR up to $17.8 \%$. Also we'll gain a good improvement in the lidar range and the detector's averaging time. Where, we can relate SNR improvement with the detector's averaging time improvement $\left(\tau_{\text {imp }}^{\text {det }}\right)$ as: $\tau_{\text {imp }}^{\text {det }}=\left(S N R{ }_{i m p}\right)^{2}$. So, an improvement of detector's averaging time (i.e., reducing the required detector's averaging time) of, $\tau_{i m p}^{\text {det }}=(0.18)^{2} \approx 3.2 \%$, can be achieved from a $17.8 \%$ lidar SNR improvement. 


\section{CONCLUSIONS AND FUTURE WORKS}

In comparison with the classical design of lidar receiver subsystem, it does not take into account that in the receiving optics the detected images are placed on a line forming an angle with the imaging plane of receiver telescope, in such a case GF is too small. Based on our proposed design to replace the classical lidar receiver optical design with a new design that attain significant lidar SNR improvements by minimizing the detected sky BGP if we set the receiver round aperture in the proper position with a smaller size. Simulated numerical results for a biaxial lidar have been shown the telescope best selection is the one with smaller $\mathrm{f}$ to ensure having the minimum FOV that accepts all return signals for the entire ranges, while at the same time minimizing detected BGP and maximizing lidar SNR and attainable lidar ranges. The improvement in lidar SNR was up to $17.8 \%$. This in turns lead to a good improvement in the lidar range and the detector's averaging time. A reducing of the required detector's averaging time of, $\tau_{\text {imp }}^{\text {det }} \approx 3.2 \%$, can be achieved.

\section{REFERENCES}

1. Zuev V., V. Burlakov, and A. El'nikov, J. Aerosol Sci. 29 1179-1187 (1998).

2. Barnaba F, and G. Gobbi, J. Geophys. Res. 106, 3005-3018 (2001).

3. Douglass L. R., M.R. Schoeberl, S.R. Kawa and E.V. Browell, J. Geophys Res. 106, 9879-9895 (2000).

4. B. Stein, C. Wedekind, H. Wille, F. Immler, M. Müller, L. Wöste, M. del Guasta, M. Morandi, L. Stefanutti, A. Antonelli, P. Agostini, V. Rizi, G. Readelli, V. Mitev, R. Matthey, R. Kivi, and E. Kyrö, J. Geophys. Res. 104, 23983-23993 (1999).

5. Measures R.M ," Laser Remote-Sensing equation," in Laser Remote Sensing: Fundamentals and Applications, Publisher, Wiley New York, 1984, pp 237-280.

6. R. Velotta, B. Bartoli, R. Capobianco, L. Fiorani, and N. Spinelli, Appl. Opt. 37, 6999-7007 (1998).

7. Agishev, Ravil R. and Adolfo Comeron, Appl. Opt. 41, 7516-7521 (2002).

8. Y. Hassebo, R. Agishev, F. Moshary, S. Ahmed "Optimization of Biaxial Raman Lidar receivers to the overlap factor effect” in 3rd. NOAA CREST Symposium, Hampton, VA USA, April 2004.

9. K. Sassen and R. L. Petrilla, Appl. Opt. 25, 1450- 1459 (1986).

10. P. Bruscaglioni, G. Zaccanti, L. Pantani, and L. Stefanutti, Int. J. Remote Sensing 4, 399-417 (1983).

11. R. J. Allen and C. M. R. Platt, Appl. Opt. 16, 3193-3199 (1977).

12. K. Stelmaszczyk, M. Dell'Aglio, S. Chudzyn' ski, T. Stacewicz, and L. Wöste, Appl. Opt. 44, 1323-1331 (2005).

13. H. Kuze, H. Kinjo, Y. Sakurada, and N. Takeuchi, Appl. Opt. 37, 3128-3132 (1998).

14. Yasser Y. Hassebo, B. Gross, M. Oo, F. Moshary, and S. Ahmed, Appl. Opt. 45, (in press) (2006).

15. Zuev V., V. Burlakov, and A. El'nikov, Ten Years (1986-1995) of lidar observations of temporal and vertical structure of stratospheric aerosol over Siberia. J. Aerosol Sci. 29 1179-1187 (1998).

16. Barnaba F, and G. Gobbi, "Lidar estimation of tropospheric aerosol extinction, surface area and volume: Maritime and desert-dust cases. J. Geophys. Res., 106 (D3), 3005-3018 (2001).

17. Douglass L. R., M.R. Schoeberl, S.R. Kawa and E.V. Browell, "A composite view of ozone evolution in the $1995-1996$ northern winter polar vortex developed from airborne lidar and satellite observations. J. Geophys Res., 106 (D9), $9879-9895$ (2000).

18. B. Stein, C. Wedekind, H. Wille, F. Immler, M. Müller, L. Wöste, M. del Guasta, M. Morandi, L. Stefanutti, A. Antonelli, P. Agostini, V. Rizi, G. Readelli, V. Mitev, R. Matthey, R. Kivi, and E. Kyrö, "Optical classification, existence temperatures, and coexistence of different polar stratospheric cloud types,” J. Geophys. Res. 104 (D19), 23983-23993 (1999).

19. Measures R.M , Laser Remote Sensing:Fundamentals and Applications, Wiley New York, 1984.

20. R. Velotta, B. Bartoli, R. Capobianco, L. Fiorani, and N. Spinelli, "Analysis of the receiver response in lidar measurements," Appl. Opt. 37, 6999-7007 (1998).

21. Agishev, Ravil R. and Adolfo Comeron "Spatial filtering efficiency of monostatic biaxial lidar: analysis and applications", App. Opt. 41, 7516-7521 (2002).

22. Y. Hassebo, R. Agishev, F. Moshary, S. Ahmed "Optimization of Biaxial Raman Lidar receivers to the overlap factor effect" 3rd. NOAA CREST Symposium, Hampton, VA USA, April 2004.

23. K. Sassen and R. L. Petrilla, "Lidar depolarization from multiple scattering in marine stratus clouds," Appl. Opt. 25, 14501459 (1986).

24. P. Bruscaglioni, G. Zaccanti, L. Pantani, and L. Stefanutti, "An approximate procedure to isolate single scattering contribution to lidar returns from fogs," Int. J. Remote Sensing 4, 399-417 (1983).

25. R. J. Allen and C. M. R. Platt, "Lidar for multiple backscattering and depolarization observations," Appl. Opt. 16, 31933199 (1977). 
26. K. Stelmaszczyk, M. Dell’Aglio, S. Chudzyn' ski, T. Stacewicz, and L. Wöste “Analytical function for lidar geometrical compression form-factor calculations", J. App. Opt. 44, No. 7 (2005).

27. H. Kuze, H. Kinjo, Y. Sakurada, and N. Takeuchi "Field-of-view dependence of lidar signals by use of Newtonian and Cassegrainian telescopes", J. App. Opt.37, No. 15, (1998).

28. Yasser Y. Hassebo, B. Gross, M. Oo, F. Moshary, and S. Ahmed "Polarization discrimination technique to maximize LIDAR signal-to-noise ratio for daylight operations", J. App. Opt. 45, No. 22 (in press) (2006). 
Copyright of AIP Conference Proceedings is the property of American Institute of Physics and its content may not be copied or emailed to multiple sites or posted to a listserv without the copyright holder's express written permission. However, users may print, download, or email articles for individual use. 